\title{
SARS-CoV-2, an Underestimated Pathogen of the Nervous System
}

\author{
Shweta Jakhmola ${ }^{1} \cdot$ Omkar Indari $^{1} \cdot$ Sayantani Chatterjee ${ }^{1} \cdot$ Hem Chandra Jha ${ }^{1}$ (D)
}

Accepted: 10 September 2020 / Published online: 28 September 2020

(C) Springer Nature Switzerland AG 2020

\begin{abstract}
Numerous clinical studies have reported neurological symptoms in COVID-19 patients since the spread of severe acute respiratory syndrome coronavirus 2 (SARS-CoV-2), apart from the atypical signs of pneumonia. Angiotensin-converting enzyme-2 (ACE-2), a potential receptor for SARS-CoV-2 entry, is expressed on various brain cells and cerebral parts, i.e., subfornical organ, paraventricular nucleus, nucleus of the tractus solitarius, and rostral ventrolateral medulla, as well as in non-cardiovascular areas such as the motor cortex and raphe. The resident CNS cells like astrocytes and microglia also express ACE-2, thus highlighting the vulnerability of the nervous system to SARS-CoV-2 infection. Additionally, transmembrane serine protease 2 (TMPRSS2) and furin facilitate virus entry into the host. Besides, the probable routes of virus entry into the nervous system include the hematogenic pathway, through the vagus, the olfactory nerve, or the enteric nervous system. However, the trajectory of SARS-CoV-2 to the brain needs investigation. Furthermore, a Th17-mediated cytokine storm is seen in COVID-19 cases with higher levels of IL-1 $\beta / 2 / 7 / 8 / 9 /$ 10/17, GM-CSF, IFN- $\gamma$, TNF- $\alpha$, CXCL-10, MCP1, and MIP1 $\alpha / \beta$. Some cytokines can cross the blood-brain barrier and activate the brain's immune cells to produce neural cytokines, leading to neuronal dysfunctions. Nonetheless, most of the neurological conditions developed due to viral infections may not have effective and registered treatments. Although, some antivirals may inhibit the virus-mediated pathogenesis and prove to be suitable in COVID-19 treatment. Therefore, clinicians' and researchers' collective expertise may unravel the potential of SARS-CoV-2 infection to prevent short-term and long-term CNS damage.
\end{abstract}

Keywords SARS-CoV-2 · COVID-19 · ACE- 2 - Nervous system $\cdot$ Cytokine storm

\section{Introduction}

The initial cases of severe acute respiratory syndrome coronavirus 2 (SARS-CoV-2) infection appeared in December 2019 in Hubei province, China [1]. Since then, it has become a global threat. Besides systemic and respiratory ailments, 36.4\% of coronavirus disease of 2019 (COVID-19) patients developed neurological symptoms [2]. Additionally, taste, smell, and visual impairments are reported in several cases of COVID-19 [2]. SARS-CoV-2, a human CoV $(\mathrm{HCoV})$ belongs to $\beta$-coronaviruses, and various clinical and pre-clinical studies have reported potential neurovirulent properties of these viruses [3]. Furthermore, the presence of

This article is part of the topical collection on Covid-19

Hem Chandra Jha

hemcjha@iiti.ac.in

1 Infection Bio-engineering Group, Discipline of Biosciences and Biomedical Engineering, Indian Institute of Technology Indore, Lab No. 302, School Building, Indore, Madhya Pradesh 453552, India
SARS-CoV-2 in cerebrospinal fluid (CSF) of COVID-19 patients is confirmed through genome sequencing [4]; however, experimental evidence is needed to validate virusmediated neurological damage. Moreover, acute necrotizing hemorrhagic encephalopathy (ANE) was observed in brain computed tomography and magnetic resonance imaging of a COVID-19 patient [5]. This rare complication is often associated with intracranial cytokine storms and points towards the indirect mode of SARS-CoV-2 influence on the brain [5]. Also, a detailed study of brain tissue distribution of angiotensin-converting enzyme-2 (ACE-2), a potential receptor for SARS-CoV-2 entry [6], may shed light on potential SARS-CoV-2-induced neurological alterations. Elaborate ACE-2 expression studies state that the receptor is preferentially expressed in the endothelium, vascular smooth muscle cells, and on the surface of a variety of the central nervous system (CNS) and peripheral nervous system (PNS) cells [7-9]. Additional plausible entry routes to the brain may include the hematogenic pathway, transmission through the vagus, the olfactory nerve, or the enteric neuron (Fig. 1a) [10]. In brief, here we recapitulate varied aspects of COVID-19-related neurological manifestations. 


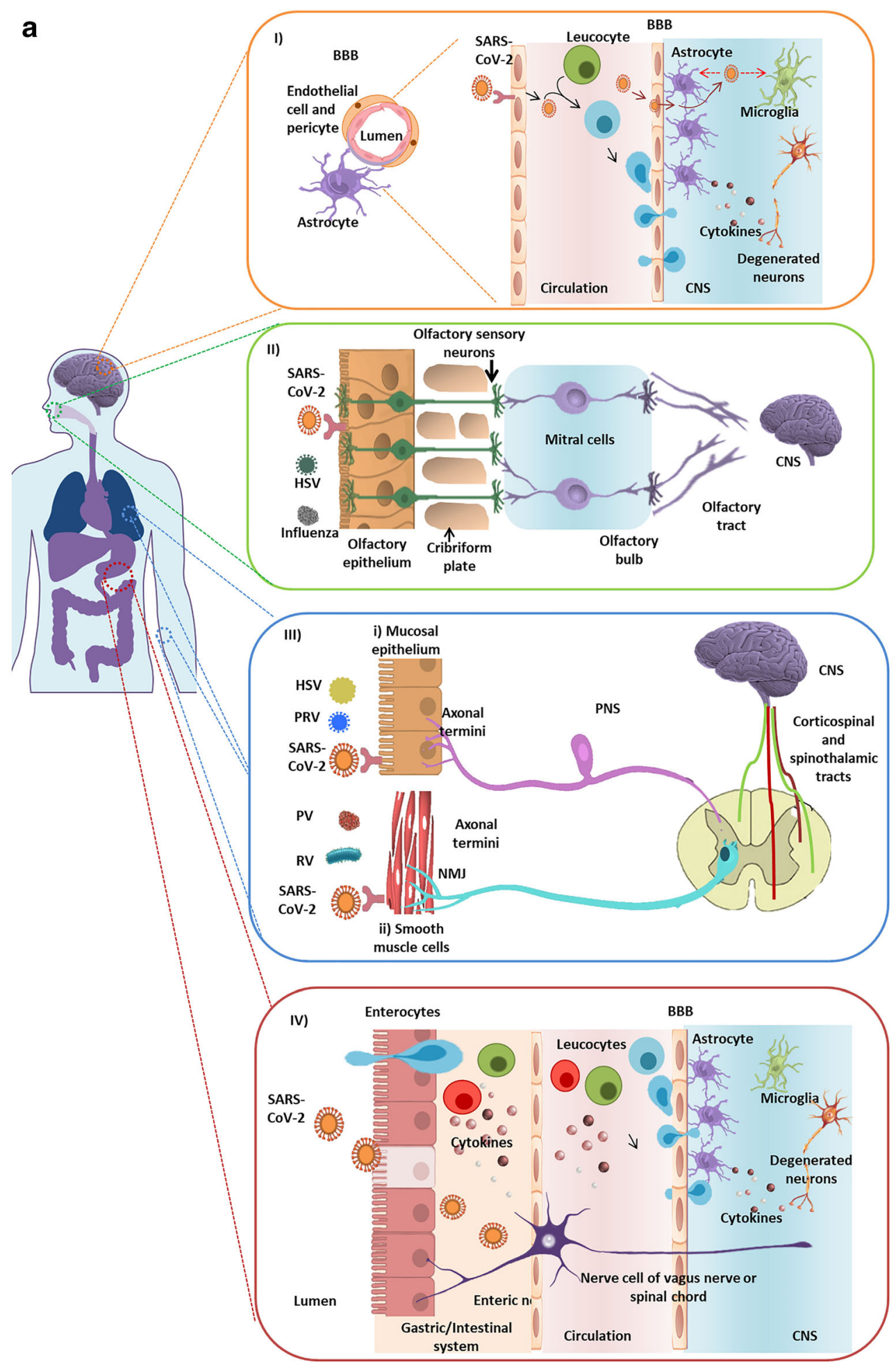

\section{Clinical Outcomes of Virus-Mediated Brain Dysfunction: More Prevalent Than Acknowledged?}

The association of viruses with neural disorders is widely popular, although the relativity is still disputed. Neurodegenerative diseases, affecting approximately 37 million people worldwide, include degenerative ailments of the nervous system - the brain, spinal cord, and nerves [11]. Numerous genomic and proteomic studies unravel the similarities between virusmediated and classical neurodegeneration or neuropathies [12, 13]. Viruses introduce alterations in the functioning of neurons 
4 Fig. 1 a Virus entry routes into the central nervous system (CNS). (I) The virus in the bloodstream may infect the peripheral immune cells. These infected leukocytes may traverse the blood-brain barrier (BBB) composed of specialized tight junctions, endothelial cells, pericytes, and astrocytes. In addition, the virus may also cross the BBB which could be severed due to the action of the cytokines or may enter the cerebrospinal fluid (CSF) by direct interaction with the brain microvascular endothelium cells. Both the mechanisms result in alterations in the brain homeostasis and aggravate cytokine production within the CNS (II) Several viruses like HSV and influenza viruses are known to infect the olfactory epithelial membrane. SARS-CoV-2 may also infect and damage olfactory sensory neurons (OSNs) in the epithelium lining. The damage may be direct or due to the production of cytokines produced by the accessory cells in the olfactory system. The virus may anterogradely reach the olfactory bulb through the cribriform plate. Finally, the virus may potentially gain entry into the CNS through the mitral cells along the olfactory tract. (III) Alpha herpesviruses (e.g. HSV-1, PRV) and polio virus (PV) along with rabies viruses (RV) may migrate to the CNS through the peripheral nerves. (i) Viruses may infect the mucosal epithelium following infection of the axonal termini of the peripheral nerves. The virus may spread to the spinal cord through retrograde axonal transport. (ii) Viruses infect the smooth muscle cells and spread through the neuromuscular junctions (NMJ) from muscles into the sensory/motor neurons of PNS ganglia. (IV) The gastrointestinal epithelium expresses ACE-2 receptors. Therefore, the cells may be easily infected by the virus. The virus may directly invade the enteric nervous system or indirectly it may prime the immune cells which may result in delayed neurological impairment. b SARS-CoV-2-mediated cytokine storm. After attachment and entry into the epithelial cells through ACE-2 receptor, the virus may activate the pro-inflammatory pathway through TLR or NF-KB signaling followed by the formation of inflammasome. Various pro-inflammatory cytokines and chemokines released due to this autonomous intrinsic defense mechanism include CCL-2, CCL-4, CXCL-10, and IL-6. These proteins attract various immune cells in the circulation like the monocytes, macrophages, $\mathrm{T}$ cells, and neutrophils at the site of infection. Additionally, the situation is worsened by production of TNF- $\beta$, IL- 6 , IL- 4 , IL-12, and IL-23 by the T lymphocytes, which further accumulate the immune cells establishing a pro-inflammatory feed-back loop. These cytokines may damage the BBB and activate astrocytes and microglia, the CNS resident immune cells. In response, the activated microglia and astrocytes produce IL- $1 \beta$, IL-6, TNF- $\alpha$, and IL- 8 . Elevated levels of these inflammatory cytokines can impart neurotoxic effects leading to neuronal dysfunction and various CNS disease-associated pathologies

directly or indirectly. The neurotropic viruses afflict neurons through cell lysis, necrosis, or apoptosis [14]. Indirectly, the viruses damage the neurons by manipulating or attacking the host immune responses. In the CNS, the virus can activate both the adaptive and innate immune responses [15]. Common pathways involved in the activation of the immune responses include the TLR mostly 3, 7, and 8 mediated damage, the release of free radicals, and inflammation [15]. Although, not always does the CNS immune response lead to detrimental outcomes as they usually assist in repair and regeneration [15].

Multiple studies mention the corroboration of infectious respiratory organisms as causative agents of various neurological diseases [16]. Respiratory syncytial virus (RSV) is known to infect the lower respiratory tract, cause infections in the immunocompromised patients, and target the CNS [16]. Often the virus is detected in the CSF samples of the patients exhibiting symptoms like seizures and convulsions, along with signs of ataxia, hormonal dysfunction, and encephalopathies [16]. Also, in vivo studies demonstrate the movement of the virus intranasally to the CNS [10]. Another respiratory virus that affects the infants and has neurovirulent abilities is the human metapneumovirus (hMPV) [17]. The virus is substantially detected in encephalopathic patients' CSF samples, although studies demonstrating the virus' neuroinvasive properties are to be conducted [18]. Furthermore, Hendra virus $(\mathrm{HeV})$ and Nipah virus (NiV) affect humans and cause lung damage, pneumonia, along with hemorrhagic and necrotizing alveolitis [19]. Typical signs of neurological disturbance, including convulsions, seizures with motor deficits, and febrile encephalitic syndrome, are observed due to infection caused by these zoonotic viruses [19]. Animal studies show the olfactory nerve to be the main route to the CNS [20].

Also, the flu-causing influenza viruses account for numerous seasonal epidemics with a severe lethality rate, approximately a million cases per year [21]. Additionally, the viruses also affect the brain and are linked to encephalitis, febrile seizure, acute necrotizing encephalopathy, and syndromes like the Reye syndrome and Guillain-Barré syndrome [22]. According to some animal studies, the influenza virus can alter the brain homeostasis by traveling to the brain through the vagus nerve or the olfactory route [23, 24]. Intriguing, its association with Parkinson's disease (PD) and multiple sclerosis (MS) is also mentioned [25]. Many encephalitis lethargica and postencephalitic parkinsonism cases followed by the 1918 "Spanish" flu pandemic, caused by influenza A (H1N1), make the involvement of the flu virus evident [26]. Viruses like the enteroviruses polioviruses (PV), coxsackieviruses (CV), echoviruses, and human rhinoviruses (HRV) are known to invade the CNS [27]. Studies describe HRV-induced meningitis and cerebellitis [27]. EV-A71 (hand-foot-mouth disease (HFMD)) and D68 outbreaks are associated with neurological complexities like myelitis (AFM), meningitis, and encephalitis [27].

The HCoVs can aggravate various neuropathologies. $\mathrm{HCoVs}$ are related to the neuroinvasive animal CoVs like porcine hemagglutinating encephalomyelitis virus, feline $\mathrm{CoV}$, and the mouse hepatitis virus, which is used to generate MS models [28, 29]. Furthermore, a study conducted to demonstrate the relation between the HCoVs (229E and OC43) with MS and other neurological disorders involves identifying viral RNA in human brain autopsies [30]. Importantly, CoVOC43 and CoV-229E are found in the CSF of PD patients [31]. However, detailed studies are needed to differentiate the mere presence and virus-associated disease alterations. In addition, association of SARS-CoV is not just limited to the 


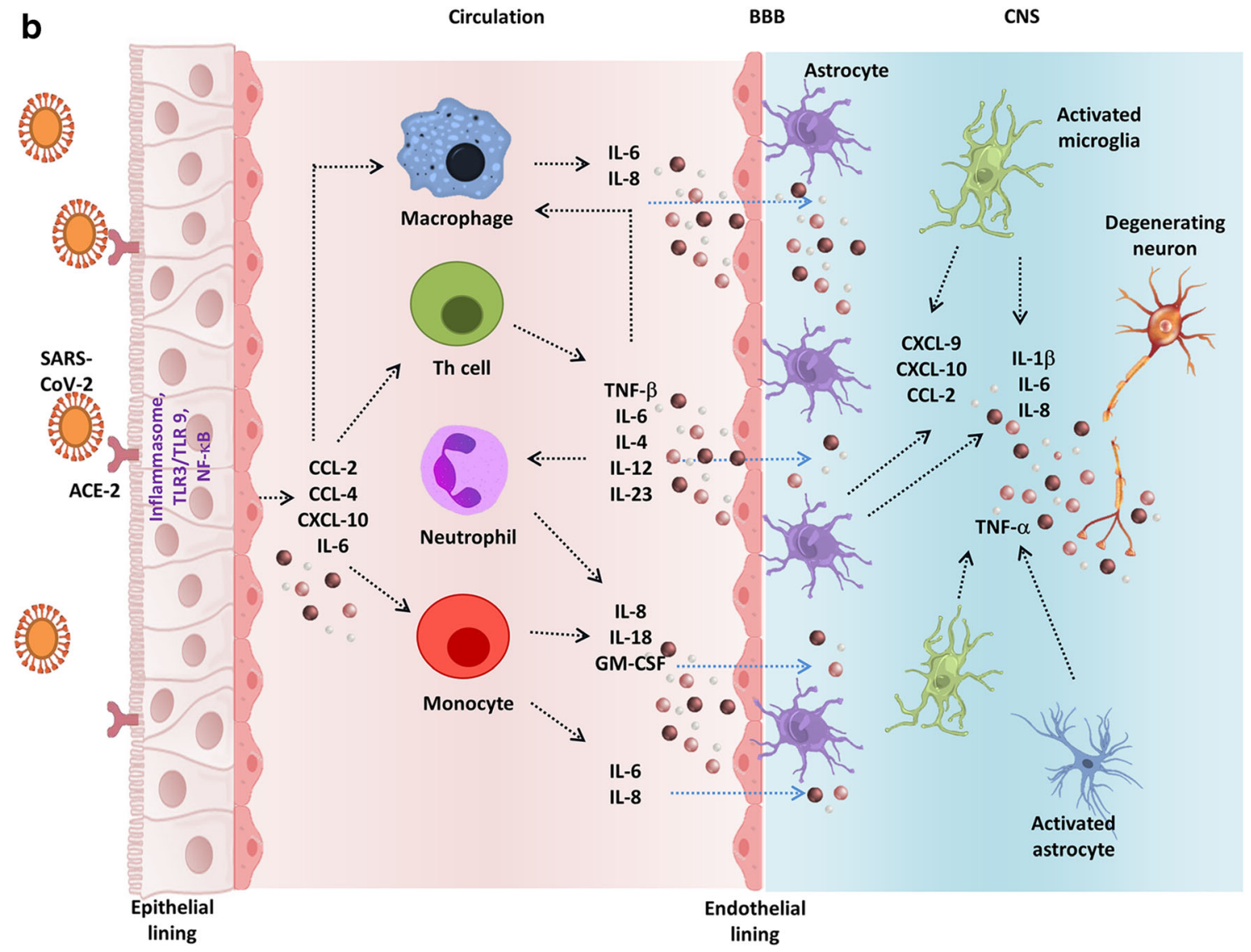

Fig. 1 (continued)

lungs; instead, it is known to infect many organs, including the CNS [7, 32-34]. The real-time quantitative PCR assay targeting the polymerase (orflab) and nucleocapsid region of the SARS-CoV confirmed the presence of SARS-CoV in CSF and serum of the infected patients $[35,36]$. A report suggests the association of status epilepticus with SARS [35]. Hospitalized children with the acute encephalitis-like syndrome were positive for anti-SARS-CoV IgM [37]. SARS$\mathrm{CoV}$ is associated with demyelinating pathology and found in the brain parenchyma of MS patients [5, 28]. Neurological symptoms are also associated with MERS-CoV [38]. These examples impress on the connection of $\mathrm{HCoVs}$ with neurological dysfunctions. Therefore, the association of neurological complications with SARS-CoV-2 is not surprising.

According to a case report of SARS-CoV-2 infection, virus RNA was determined in the patient's CSF; however, the nasopharyngeal swabs tested negative [4]. Currently, evidence to state the neuropathogenesis of the SARS-CoV-2 in COVID-19 remains scarce. Nevertheless, reports suggest that SARS-CoV-2 can cause meningitis and encephalitis [4]. Variable neurological symptoms are displayed by the COVID-19 patients like PNS symptoms, including hypogeusia, hyposmia, hypoplasia, and neuralgia vertigo, and CNS dysfunctions like cephalgia, impaired consciousness, seizures, ataxia, and acute cerebrovascular disease, with headache and dizziness being the most common $[39,40]$. Neurological manifestations are common in many COVID-19 patients like anosmia, an early COVID-19 symptom $[2,41-43]$. Though seizures are seldom reported in COVID-19 patients, and usually indicate an ischemic stroke, meningitis, or cerebral hypoxia, its association with comorbidities like hypocalcemia or drugs remains elusive [44].

The neurological alterations caused by the virus may result from direct CNS/PNS attack or indirect influence on various organs that later affect the nervous system. For example, hypertension, common COVID-19 comorbidity, results in blood-brain barrier (BBB) impairment and may enhance the risk of COVID-19-related cerebral complexities [45, 46]. A hypothesis relates neuronal damage to the respiratory stress from deteriorated lung conditions [47]. The oxygen deprivation may result in multiple organ failure and may affect the brain [47]. Besides, patients considered during the earlier studies of the SARS-CoV pandemic displayed axonal motor sensory neuropathy and myopathy [48]. However, it remains unclear if the illness was virus-mediated or an outcome of high drug doses [48]. Nevertheless, the effect of the SARS-CoV-2 on PNS is noteworthy as Guillain-Barre, Miller-Fisher syndrome, and polyneuritis cranialis are reported in COVID-19 
[49-54]. Development of rhabdomyolysis, neuralgia, and myalgia in SARS-CoV-2-infected patients further support the virus' ability to affect PNS [52-54]. A study reported elevated creatinine kinase and muscle pain in $10.7 \%$ of patients with severe COVID-19 [2]. Furthermore, some COVID-19 patients with neurological symptoms might have a prior history of neurological complications or maybe treated for viral infections. Hence, it is necessary to treat such cases using drugs with properties of high bioavailability in the brain. We have summarized information like the mode of action and brain or $\mathrm{CSF} /$ plasma ratio of a few antivirals, which have shown promising outcomes in COVID-19 treatment (Table 1) [70, 71]. The use of efficient BBB penetrating drugs may be preferred during this pandemic to minimize the onset of neurological consequences of SARS-CoV-2 infection.

\section{Neurological Alterations Due to Cytokine Storm: a Result of Host Immunity and SARS-CoV-2 Combat}

Indirectly the viruses may damage the neurons by manipulating or attacking the host immunity [15]. In the CNS, SARS-CoV-2 can activate both the adaptive and innate immunity [15]. Thelper cell 17 (Th17)-mediated cytokine storm, evident in virus infections, is seen in COVID-19 with neurological manifestations (Fig. 1b) [72, 73]. Clinical studies report systemic inflammation involving enhanced cytokines, particularly IL-1 $\beta$, IL-6, IL-10, granulocyte colony-stimulating factor, granulocyte-monocyte colony-stimulating factor, $\mathrm{C}-\mathrm{X}-\mathrm{C}$ motif chemokine ligand 10 (CXCL10), MCP-1, macrophage inflammatory proteins $1-\alpha$, and tumor necrosis factor $\alpha$ in COVID-19. Additionally CD4+ and $\mathrm{CD} 8+\mathrm{T}$ cell lymphopenia and decreased secretion of IFN- $\gamma$ in severe cases of COVID-19 are reported (Fig. 1a) [28, 37, 72]. Intriguingly, a study suggests that an MS patient undergoing ocrelizumab (an immunosuppressive drug) therapy diagnosed positive for COVID-19 does not display serious complications [74]. The increased levels of cytokines may escalate vascular and BBB permeability and inflammation $[74,75]$. This information supports the hypothesis that increased BBB permeability allows virus entry into the CNS, leading to COVID-19-related neurological complexities. Some cytokines released in the circulation can cross the BBB and activate the resident brain immune cells like microglia and astrocytes to produce neural cytokines, further worsening the condition (Fig. 1b) [76]. Astrocytes regulate a wide variety of functions, which may aggravate neuroinflammation. Microglia mature into macrophages and may engulf the neighboring neurons on activation [77, 78]. Furthermore, microglia are the primary source of pro-inflammatory cytokines, nitric oxide, prostaglandin $\mathrm{E} 2$, and reactive oxygen and nitrogen species [77]. Microglia express ACE-2, along with ACE and AT1 [79]. These receptors play a significant role in microglia activation and balance the pro-inflammatory or antiinflammatory effects [80]. More specifically, SARS-CoV-2 infection can hamper the ACE-2-mediated signaling, creating a glitch in the AT1 receptor-mediated path, thereby inducing a pro-inflammatory response [80]. In vivo studies suggest induction of pro-inflammatory cytokines in microglia and the mouse brain and spinal cord [81]. The situation becomes dreadful when the pro-inflammatory substances produced by astrocytes and microglia fenestrate the BBB [77, 78].

Besides, SARS-CoV infects the myeloid cells and manipulates the innate immune system to ease its propagation to other tissues (Fig. 1a) [82]. These persistently infected leukocytes act as reservoirs of the neuroinvasive $\mathrm{HCoV}$ and can be held responsible for long-term neurological sequelae [83]. Therefore,

Table 1 Antiviral drugs proposed in COVID-19 treatment along with their mechanism of action, associated complications, and CSF to plasma ratio

\begin{tabular}{|c|c|c|c|c|}
\hline Drug name & Mechanism & Viruses affected by the drug & Brain/plasma ratio & $\begin{array}{l}\text { Neurological complications } \\
\text { the drug is active against }\end{array}$ \\
\hline Lopinavir/ ritonavir & Inhibit the viral proteases & HIV & $0.02 \% / 1.23 \%[55]$ & HAND [56] \\
\hline Darunavir & Inhibit the viral proteases & HIV & $0.88 \%[57]$ & HAND [57] \\
\hline Favipiravir & Inhibit the viral proteases & Influenza $\mathrm{A}$ and $\mathrm{B}$ & Low [58] & - \\
\hline Remdesivir & $\begin{array}{l}\text { Nucleotide analog - blocks viral nucleotide } \\
\text { synthesis to stop viral replication }\end{array}$ & Ebola virus & $<5 \%[59]$ & - \\
\hline Ribavirin & Inhibit viral polymerase & RSV, hepatitis C virus & $70 \%[60]$ & $\begin{array}{l}\text { Nipah virus-associated } \\
\text { encephalitis [61], } \\
\text { neurocognitive conditions[62] }\end{array}$ \\
\hline Oseltamivir & Inhibit viral neuraminidase & Influenza A and B & $2.1 \%[63]$ & $\begin{array}{l}\text { Influenza-associated } \\
\quad \text { encephalitis }[64,65] \text {, PD [66] }\end{array}$ \\
\hline Amantadine & Inhibits viral M2 protein (an ion channel) & Influenza A & $76 \%[67]^{*}$ & $\begin{array}{l}\text { Influenza-associated } \\
\text { encephalitis [68], PD [69] }\end{array}$ \\
\hline
\end{tabular}

*CSF/serum ratio. HAND HIV-associated neurocognitive disorders, $P D$ Parkinson's disease, $R S V$ respiratory syncytial virus. The brain to plasma ratio or CSF to plasma ratio has been denoted for each drug assuming that brain penetration is similar between rodents, non-human primates, and human patients 
the possibility of such cases of persistent SARS-CoV-2 infection may appear in the future. Notably, peripheral inflammatory reactions observed in COVID-19 may result in symptoms of neurological disorders [84]. Cytokine storms may influence the CNS and enhance the severity of COVID-19 patients to develop ANE, meningitis, and hemorrhage $[5,85]$. Therefore, it is necessary to identify the mechanism behind SARS-CoV-2induced cytokine storms and the course of release of the cytokines during the infection. The contribution of the proinflammatory cytokines alone and the direct tissue damage caused by the virus needs to be addressed. The indirect influence of systemic inflammation on the CNS by targeting the proinflammatory mediators will be worth investigating.

\section{ACE-2 Dependent and Independent Infection of the Nervous System in COVID-19}

It is found that ACE- 2 is expressed in various brain regions, like the subfornical organ, the nucleus of the tractus solitarius, and rostral ventrolateral medulla, as well as in non-cardiovascular areas such as the motor cortex and raphe [86]. According to a spatial distribution analysis, ACE-2 is expressed in substantia nigra and brain ventricles [87-89]. The protein's cell type distribution revealed both excitatory and inhibitory neurons, pericytes and endothelial cells, and glial cells like astrocytes and oligodendrocytes in human middle temporal gyrus and posterior cingulate cortex express ACE-2, unlike the cells in the region of the prefrontal cortex [9]. Additionally, the hippocampus has few ACE-2 expressing cells [9]. Studies report that angiotensin II downregulates the expression of ACE-2 in neonatal rat cerebellar or medullary astrocytes [90]. Therefore, the predominant expression of ACE-2 in the brain hints towards the virus's potential to infect the CNS.

Furthermore, brain endothelial and smooth muscle cells of the blood vessels express ACE-2 [7]. The virus may enter into the CNS through the hematogenic pathway, subsequently crossing the BBB [91]. A post-mortem study of the frontal lobe of a COVID-19 patient reports virus presence in neurons and capillary endothelial cells [92]. Infection of endothelial cells may allow the virus to pass from the respiratory tract to the blood. The virus in the peripheral system can move into the cerebral circulation, where the blood's sluggish movement may facilitate the viral S protein interaction with the ACE-2 expressed on the endothelial lining of the brain (Fig. 1a) [93]. Another speculated entry route for SARS-CoV-2 may be through the enteric nervous system upon infection of enterocytes [94, 95]. Enterocytes express high magnitudes of ACE-2 [7]. Once inside the brain, the virus can infect the neural cells, astrocytes, and microglia. These cells express ACE-2, thus initiating the viral budding cycle followed by neuronal damage and inflammation (Fig. 1a) [96].
Moreover, multiple transcriptome studies show and validate ACE-2 expression levels in various non-neuronal cells of olfactory mucosa [97]. Studies support the viral susceptibility of the mucosal cells, sustentacular cells, Bowman's cells, and olfactory stem cells $[98,99]$. Loss of smell in COVID-19 is marked by potential deterioration of olfactory stem cells and other accessory cells [98]. Also, a high-throughput single-cell expression study mentioned no ACE-2 expression in olfactory covering glia, microvillar cells, and immature or mature olfactory sensory neurons [100]. It is speculated that SARS-CoV-2 on binding may stimulate olfactory receptor neurons (ORNs) to exert an exaggerated immune response. Earlier studies with SARS-CoV have established infection of the brain through ORNs [101]. Studies describing the transneuronal/transsynaptic movement of the SARS-CoV already exist. Rabies viruses can take over the vesicular axonal transport machinery to disseminate in the brain (Fig. 1a) [102]. Human herpesvirus-6 (HHV-6) propagates in olfactory endothelial (OE) cells before invading the brain [93]. These studies enable to predict and support the movement of SARS-CoV-2 through the vesicular axonal pathway in an anterograde fashion through the olfactory nerve and facilitate brain infection [102] (Fig. 1a). Also, the virus may directly reach the CSF around the olfactory nerve fibers from OE cells [82]. A probable trajectory of SARS-CoV-2 to the brain may be via high-ACE-2-expressing non-neuronal $\mathrm{OE}$ cells to low-ACE-2-expressing mature ORNs along the olfactory axons. This mechanism highlights the ACE-2 independent process of virus spread.

Lastly, the expression of transmembrane serine protease 2 (TMPRSS2) in human olfactory mucosa may further worsen the case of SARS-CoV-2 infection [97]. A study demonstrates that respiratory epithelial cells express TMPRSS2 without ACE-2 [103]. The mosaic distribution of TMPRSS2 in mature ORNs is reported [104]. Therefore, the virus can preferentially gain entry into the PNS through one of the two epithelial cell types in the nose, either the goblet cells or the ciliated cells. TMPRSS2, in collaboration with furin, accelerates SARSCoV-2 entry [105]. Furin, a host serine endoprotease, is particularly of neurological relevance. In general, furin can activate neuronal growth factors and influence CNS homeostasis [106]. However, upon attachment of SARS-CoV-2 with ACE-2, the enzyme generates an active $\mathrm{S}$ protein through irreversible cleavage of the precursor protein [105]. The protein S1/S2 subunits separate, which subsequently facilitate virus entry into the host [105]. Thus, exploring the possible avenues of SARS-CoV-2 entry and impact on CNS is the need of the hour.

\section{Conclusion}

Various clinical reports have made the association of SARSCoV-2 with neurological dysfunction prominent. COVID-19- 
associated neurological severity is primarily associated with cytokine storms. The earlier identified SARS-CoV is already known to suppress the host antiviral response and activate the pro-inflammatory pathways. Briefly, it would be crucial to analyze the IFN-antagonizing and inflammasome-activating properties of SARS-CoV-2. Furthermore, the interaction of SARS-CoV-2 and ACE-2-expressing neuronal/glial cells may facilitate virus entry into the nervous system through different routes. Thus, the nervous system's involvement in COVID-19 may be more than the current situation apprehends, therefore referring to the virus as an underestimated pathogen. Medical expert clinicians and researchers' collaboration may address the enhanced incidents of neural dysfunctions in infected individuals. After identifying initial neurological damages, careful monitoring of COVID-19 patients in the long term is also necessary.

Acknowledgments We thank the Ministry of Human Resource and Development and Department of Biotechnology, Govt. of India for fellowship to Shweta Jakhmola and Omkar Indari, respectively, in the form of a research stipend. We appreciate our lab colleagues for insightful discussions and advice. We gratefully acknowledge the Indian Institute of Technology Indore for providing facilities and support.

Authors' Contributions Conceptualization, data curation, formal analysis, investigation: SJ, OI, SC. Methodology, project administration, resources, supervision: SJ, HCJ. Validation: HCJ. Visualization, roles/ writing - original draft: SJ. Writing- review and editing: SJ, HCJ, OI.

\section{Compliance with Ethical Standards}

Conflict of Interest The authors declare that they have no conflict of interest.

Disclaimer The funding organization has not played any role in the study design or the preparation of the manuscript.

\section{References}

1. Chan JF-W, Yuan S, Kok K-H, et al. A familial cluster of pneumonia associated with the 2019 novel coronavirus indicating person-toperson transmission: a study of a family cluster. Lancet. 2020;395: 514-23. https://doi.org/10.1016/S0140-6736(20)30154-9.

2. Mao L, Jin H, Wang M, Hu Y, Chen S, He Q, et al. Neurologic manifestations of hospitalized patients with coronavirus disease 2019 in Wuhan, China. JAMA Neurol. 2020. https://doi.org/10. 1001/jamaneurol.2020.1127.

3. Steardo L, Steardo L Jr, Zorec R, Verkhratsky A. Neuroinfection may contribute to pathophysiology and clinical manifestations of COVID-19. Acta Physiol. 2020;e13473. 10.1111/apha.13473

4. Moriguchi T, Harii N, Goto J, Harada D, Sugawara H, Takamino $\mathrm{J}$, et al. A first case of meningitis/encephalitis associated with SARS-Coronavirus-2. Int J Infect Dis. 2020;94:55-8. https://doi. org/10.1016/j.ijid.2020.03.062.

5. Poyiadji N, Shahin G, Noujaim D, Stone M, Patel S, Griffith B. COVID-19-associated acute hemorrhagic necrotizing encephalopathy: CT and MRI features. Radiology. 2020;201187. https://doi. org/10.1148/radiol.2020201187
6. Wrapp D, Wang N, Corbett KS, Goldsmith JA, Hsieh C-L, Abiona O, et al. Cryo-EM structure of the 2019-nCoV spike in the prefusion conformation. Science. 2020;367:1260-3. https:// doi.org/10.1126/science.abb2507.

7. Hamming I, Timens W, Bulthuis MLC, Lely AT, Navis GJ, van Goor H. Tissue distribution of ACE2 protein, the functional receptor for SARS coronavirus. A first step in understanding SARS pathogenesis. J Pathol. 2004;203:631-7. https://doi.org/10.1002/ path. 1570 .

8. Xu P, Sriramula S, Lazartigues E. ACE2/ANG-(1-7)/Mas pathway in the brain: the axis of good. Am J Physiol Regul Integr Comp Physiol. 2011;300:R804-17. https://doi.org/10.1152/ ajpregu.00222.2010.

9. Brain tissue expression of ACE2 - summary - the human protein atlas. [cited $2020 \mathrm{Sep} 4]$. https://www.proteinatlas.org/ ENSG00000130234/brain

10. Koyuncu OO, Hogue IB, Enquist LW. Virus infections in the nervous system. Cell Host Microbe. 2013;13:379-93. https://doi. org/10.1016/j.chom.2013.03.010.

11. Karim S, Mirza Z, Kamal MA, Abuzenadah AM, Azhar EI, AlQahtani MH, et al. The role of viruses in neurodegenerative and neurobehavioral diseases. CNS Neurol Disord Drug Targets. $2014 ; 13: 1213-23$. https://doi.org/10.2174/ 187152731307141015122638 .

12. Zhou L, Diefenbach E, Crossett B, Tran SL, Ng T, Rizos H, et al. First evidence of overlaps between HIV-associated dementia (HAD) and non-viral neurodegenerative diseases: proteomic analysis of the frontal cortex from HIV+ patients with and without dementia. Mol Neurodegener. 2010;5:27. https://doi.org/10. 1186/1750-1326-5-27.

13. Shi C-S, Nabar NR, Huang N-N, Kehrl JH. SARS-coronavirus open reading frame- $8 \mathrm{~b}$ triggers intracellular stress pathways and activates NLRP3 inflammasomes. Cell Death Discov. 2019;5: 101. https://doi.org/10.1038/s41420-019-0181-7.

14. Zhou L, Miranda-Saksena M, Saksena NK. Viruses and neurodegeneration. Virol J. 2013;10:172. https://doi.org/10.1186/1743422X-10-172.

15. Amor S, Puentes F, Baker D, van der Valk P. Inflammation in neurodegenerative diseases. Immunology [Internet]. 2010;129: 154-69. Available from: https://doi.org/10.1111/j.1365-2567. 2009.03225.x

16. Bohmwald K, Gálvez NMS, Ríos M, Kalergis AM. Neurologic alterations due to respiratory virus infections. Front Cell Neurosci. 2018;12:386. https://doi.org/10.3389/fncel.2018.00386.

17. Edwards KM, Zhu Y, Griffin MR, Weinberg GA, Hall CB, Szilagyi PG, et al. Burden of human metapneumovirus infection in young children. N Engl J Med. 2013;368:633-43. https://doi. org/10.1056/NEJMoa1204630.

18. Peiris JSM, Tang W-H, Chan K-H, Khong P-L, Guan Y, Lau Y-L, et al. Children with respiratory disease associated with metapneumovirus in Hong Kong. Emerg Infect Dis. 2003;9: 628-33. https://doi.org/10.3201/eid0906.030009.

19. Broder CC, Weir DL, Reid PA. Hendra virus and Nipah virus animal vaccines. Vaccine. 2016;34:3525-34. https://doi.org/10. 1016/j.vaccine.2016.03.075.

20. Dhondt KP, Horvat B. Henipavirus infections: lessons from animal models. Pathogens. 2013;2:264-87. https://doi.org/10.3390/ pathogens2020264.

21. Influenza (Seasonal). [cited 2020 Sep 4]. https://www.who.int/ news-room/fact-sheets/detail/influenza-(seasonal)

22. Hayase $\mathrm{Y}$, Tobita K. Influenza virus and neurological diseases. Psychiatry Clin Neurosci. 1997;51:181-4. https://doi.org/10. 1111/j.1440-1819.1997.tb02580.x.

23. Park $\mathrm{CH}$, Ishinaka $\mathrm{M}$, Takada $\mathrm{A}$, Kida $\mathrm{H}$, Kimura $\mathrm{T}$, Ochiai $\mathrm{K}$, et al. The invasion routes of neurovirulent A/Hong Kong/483/97 (H5N1) influenza virus into the central nervous system after 
respiratory infection in mice. Arch Virol. 2002;147:1425-36. https://doi.org/10.1007/s00705-001-0750-x.

24. Mori I, Nishiyama Y, Yokochi T, Kimura Y. Olfactory transmission of neurotropic viruses. J Neurovirol. 2005;11:129-37. https:// doi.org/10.1080/13550280590922793.

25. Blackmore S, Hernandez J, Juda M, Ryder E, Freund GG, Johnson RW, et al. Influenza infection triggers disease in a genetic model of experimental autoimmune encephalomyelitis. Proc Natl Acad Sci U S A. 2017;114:E6107-16. https://doi.org/10.1073/ pnas. 1620415114.

26. Henry J, Smeyne RJ, Jang H, Miller B, Okun MS. Parkinsonism and neurological manifestations of influenza throughout the 20th and 21st centuries. Parkinsonism Relat Disord. 2010;16:566-71. https://doi.org/10.1016/j.parkreldis.2010.06.012.

27. Rhoades RE, Tabor-Godwin JM, Tsueng G, Feuer R. Enterovirus infections of the central nervous system. Virology. 2011;411:288305. https://doi.org/10.1016/j.virol.2010.12.014.

28. Das SJ. A mechanism of virus-induced demyelination. Interdiscip Perspect Infect Dis. 2010;2010:109239. https://doi.org/10.1155/ 2010/109239.

29. Desforges M, Le Coupanec A, Dubeau P, Bourgouin A, Lajoie L, Dubé M, et al. Human coronaviruses and other respiratory viruses: underestimated opportunistic pathogens of the central nervous system? Viruses. 2019;12. https://doi.org/10.3390/v12010014.

30. Cristallo A, Gambaro F, Biamonti G, Ferrante P, Battaglia M, Cereda PM. Human coronavirus polyadenylated RNA sequences in cerebrospinal fluid from multiple sclerosis patients. New Microbiol. 1997;20:105-14 https://www.ncbi.nlm.nih.gov/ pubmed/9208420.

31. Fazzini E, Fleming J, Fahn S. Cerebrospinal fluid antibodies to coronavirus in patients with Parkinson's disease. Mov Disord. 1992;7:153-8. https://doi.org/10.1002/mds.870070210.

32. Ding Y, He L, Zhang Q, Huang Z, Che X, Hou J, et al. Organ distribution of severe acute respiratory syndrome (SARS) associated coronavirus (SARS-CoV) in SARS patients: implications for pathogenesis and virus transmission pathways. J Pathol. 2004;203:622-30. https://doi.org/10.1002/path.1560.

33. Gu J, Gong E, Zhang B, Zheng J, Gao Z, Zhong Y, et al. Multiple organ infection and the pathogenesis of SARS. J Exp Med. 2005;202:415-24. https://doi.org/10.1084/jem.20050828.

34. Xu J, Zhong S, Liu J, Li L, Li Y, Wu X, et al. Detection of severe acute respiratory syndrome coronavirus in the brain: potential role of the chemokine Mig in pathogenesis. Clin Infect Dis. 2005;41: 1089-96. https://doi.org/10.1086/444461.

35. Hung ECW, Chim SSC, Chan PKS, Tong YK, Ng EKO, Chiu RWK, et al. Detection of SARS coronavirus RNA in the cerebrospinal fluid of a patient with severe acute respiratory syndrome. Clin Chem. 2003;49:2108-9. https://doi.org/10.1373/clinchem. 2003.025437.

36. Ng EKO, Hui DS, Chan KCA, Hung ECW, Chiu RWK, Lee N, et al. Quantitative analysis and prognostic implication of SARS coronavirus RNA in the plasma and serum of patients with severe acute respiratory syndrome. Clin Chem. 2003;49:1976-80. https:// doi.org/10.1373/clinchem.2003.024125.

37. Li Y, Li H, Fan R, Wen B, Zhang J, Cao X, et al. Coronavirus infections in the central nervous system and respiratory tract show distinct features in hospitalized children. Intervirology. 2016;59: 163-9. https://doi.org/10.1159/000453066.

38. Arabi YM, Harthi A, Hussein J, Bouchama A, Johani S, Hajeer $\mathrm{AH}$, et al. Severe neurologic syndrome associated with Middle East respiratory syndrome corona virus (MERS-CoV). Infection. 2015;43:495-501. https://doi.org/10.1007/s15010-015-0720-y.

39. Sharifi-Razavi A, Karimi N, Rouhani N. COVID-19 and intracerebral haemorrhage: causative or coincidental? New Microbes New Infect. 2020;35:100669. https://doi.org/10.1016/j.nmni. 2020.100669
40. Finsterer J, Stollberger C. Update on the neurology of COVID-19. J Med Virol. 2020. https://doi.org/10.1002/jmv.26000.

41. Heidari F, Karimi E, Firouzifar M, Khamushian P, Ansari R, Mohammadi Ardehali M, et al. Anosmia as a prominent symptom of COVID-19 infection. Rhinology. 2020. https://doi.org/10. 4193/Rhin20.140.

42. Solomon GS. Anosmia in Alzheimer disease. Percept Mot Skills. 1994;79:1249-50. https://doi.org/10.2466/pms.1994.79.3.1249.

43. Tarakad A, Jankovic J. Anosmia and ageusia in Parkinson's disease. Int Rev Neurobiol. 2017;133:541-56. https://doi.org/10. 1016/bs.irn.2017.05.028.

44. Lu L, Xiong W, Liu D, Liu J, Yang D, Li N, et al. New onset acute symptomatic seizure and risk factors in coronavirus disease 2019: a retrospective multicenter study. Epilepsia. 2020;61:e49-53. https://doi.org/10.1111/epi.16524.

45. Huang S, Wang J, Liu F, Liu J, Cao G, Yang C, et al. COVID-19 patients with hypertension have more severe disease: a multicenter retrospective observational study. Hypertens Res. 2020;43:82431. https://doi.org/10.1038/s41440-020-0485-2.

46. Buttler L, Jordão MT, Fragas MG, Ruggeri A, Ceroni A, Michelini LC. Maintenance of blood-brain barrier integrity in hypertension: a novel benefit of exercise training for autonomic control. Front Physiol. 2017;8:1048. https://doi.org/10.3389/fphys. 2017.01048 .

47. Cormier Z. How Covid-19 can damage the brain. [cited 2020 Jul 1]. https://www.bbc.com/future/article/20200622-the-longterm-effects-of-covid-19-infection

48. Tsai L-K, Hsieh S-T, Chang Y-C. Neurological manifestations in severe acute respiratory syndrome. Acta Neurol Taiwan. 2005;14: 113-9 https://www.ncbi.nlm.nih.gov/pubmed/16252612.

49. Zhao H, Shen D, Zhou H, Liu J, Chen S. Guillain-Barré syndrome associated with SARS-CoV-2 infection: causality or coincidence? Lancet Neurol. 2020;19:383-4. https://doi.org/10.1016/S14744422(20)30109-5.

50. Guillain-Barré Syndrome associated with SARS-CoV-2 infection. IDCases. Elsevier; 2020 [cited 2020 Jul 1];20:e00771. https:// www.sciencedirect.com/science/article/pii/S2214250920300792/ pdfft?md5=b9ff1 f0fee 45c428e06eca17f1 1b5035\&pid=1-s2.0S2214250920300792-main.pdf

51. Gutiérrez-Ortiz C, Méndez A, Rodrigo-Rey S, San Pedro-Murillo E, Bermejo-Guerrero L, Gordo-Mañas R, et al. Miller Fisher syndrome and polyneuritis cranialis in COVID-19. Neurology. 2020. https://doi.org/10.1212/WNL.0000000000009619.

52. Jin M, Tong Q. Rhabdomyolysis as potential late complication associated with COVID-19. Emerg Infect Dis. 2020;26:1618 20. https://doi.org/10.3201/eid2607.200445.

53. Lippi G, Wong J, Henry BM. Myalgia may not be associated with severity of coronavirus disease 2019 (COVID-19). World J Emerg Med. 2020;11:193-4. https://doi.org/10.5847/wjem.j.1920-8642. 2020.03.013.

54. Liu K, Pan M, Xiao Z, Xu X. Neurological manifestations of the coronavirus (SARS-CoV-2) pandemic 2019-2020. J Neurol Neurosurg Psychiatry. 2020;91:669-70. https://doi.org/10.1136/ jnnp-2020-323177.

55. Ene L, Duiculescu D, Ruta SM. How much do antiretroviral drugs penetrate into the central nervous system? J Med Life. J Med Life; 2011;4. https://pubmed.ncbi.nlm.nih.gov/22514580/

56. Santos JR, Muñoz-Moreno JA, Moltó J, Prats A, Curran A, Domingo P, et al. Virological efficacy in cerebrospinal fluid and neurocognitive status in patients with long-term monotherapy based on lopinavir/ritonavir: an exploratory study. PLoS One. 2013;8:e70201. https://doi.org/10.1371/journal.pone.0070201.

57. Bartels H, Decosterd L, Battegay M, Marzolini C. Darunavir concentrations in CSF of HIV-infected individuals when boosted with cobicistat versus ritonavir. J Antimicrob Chemother. 2017;72: 2574-7. https://doi.org/10.1093/jac/dkx165. 
58. Bixler SL, Bocan TM, Wells J, Wetzel KS, Van Tongeren SA, Garza NL, et al. Intracellular conversion and in vivo dose response of favipiravir (T-705) in rodents infected with Ebola virus. Antiviral Res. 2018;151:50-4. https://doi.org/10.1016/j.antiviral. 2017.12.020.

59. Warren TK, Jordan R, Lo MK, Ray AS, Mackman RL, Soloveva $\mathrm{V}$, et al. Therapeutic efficacy of the small molecule GS-5734 against Ebola virus in rhesus monkeys. Nature. 2016;531:381-5. https://doi.org/10.1038/nature17180.

60. Connor E, Morrison S, Lane J, Oleske J, Sonke RL, Connor J. Safety, tolerance, and pharmacokinetics of systemic ribavirin in children with human immunodeficiency virus infection. Antimicrob Agents Chemother. 1993;37:532-9. https://doi.org/ 10.1128/aac.37.3.532.

61. Chong HT, Kamarulzaman A, Tan CT, Goh KJ, Thayaparan T, Kunjapan SR, et al. Treatment of acute Nipah encephalitis with ribavirin. Ann Neurol. 2001;49:810-3. https://doi.org/10.1002/ ana.1062.

62. Kraus MR, Schäfer A, Teuber G, Porst H, Sprinzl K, Wollschläger $\mathrm{S}$, et al. Improvement of neurocognitive function in responders to an antiviral therapy for chronic hepatitis C. Hepatology. 2013;58: 497-504. https://doi.org/10.1002/hep.26229.

63. Jhee SS, Yen M, Ereshefsky L, Leibowitz M, Schulte M, Kaeser $\mathrm{B}$, et al. Low penetration of oseltamivir and its carboxylate into cerebrospinal fluid in healthy Japanese and Caucasian volunteers. Antimicrob Agents Chemother. 2008;52:3687-93. https://doi.org/ 10.1128/AAC.00327-08.

64. Alsolami A, Shiley K. Successful treatment of influenzaassociated acute necrotizing encephalitis in an adult using highdose oseltamivir and methylprednisolone: case report and literature review. Open Forum Infect Dis. 2017;4:ofx145. https://doi. org/10.1093/ofid/ofx145.

65. Newland JG, Romero JR, Varman M, Drake C, Holst A, Safranek $\mathrm{T}$, et al. Encephalitis associated with influenza B virus infection in 2 children and a review of the literature. Clin Infect Dis. 2003;36: e87-95. https://doi.org/10.1086/368184.

66. Kadowaki T, Komagamine T, Suzuki K, Hirata K. Oseltamivirinduced dyskinesia in Parkinson's disease. Parkinsonism Relat Disord. 2011;17:133-4. https://doi.org/10.1016/j.parkreldis. 2010.10.013.

67. Kornhuber J, Quack G, Danysz W, Jellinger K, Danielczyk W, Gsell W, et al. Therapeutic brain concentration of the NMDA receptor antagonist amantadine. Neuropharmacology. 1995;34: 713-21 https://linkinghub.elsevier.com/retrieve/pii/ $002839089500056 \mathrm{C}$.

68. Miura M, Sugaya N, Hayashi E. Use of amantadine for influenza A encephalopathy. Kansenshogaku Zasshi. 1998;72:840-4. https://doi.org/10.11150/kansenshogakuzasshi1970.72.840.

69. Crosby N, Deane KH, Clarke CE. Amantadine in Parkinson's disease. Cochrane Database Syst Rev. 2003;CD003468. 10.1002/14651858.CD003468

70. Costanzo M, De Giglio MAR, Roviello GN. SARS-CoV-2: recent reports on antiviral therapies based on lopinavir/ritonavir, darunavir/ umifenovir, hydroxychloroquine, remdesivir, favipiravir and other drugs for the treatment of the new coronavirus. Curr Med Chem. 2020. https://doi.org/10.2174/0929867327666200416131117.

71. Smieszek SP, Przychodzen BP, Polymeropoulos MH. Amantadine disrupts lysosomal gene expression: a hypothesis for COVID19 treatment. Int J Antimicrob Agents. 2020;55: 106004. https://doi.org/10.1016/j.ijantimicag.2020.106004.

72. Wu D, Yang XO. TH17 responses in cytokine storm of COVID19: an emerging target of JAK2 inhibitor Fedratinib. J Microbiol Immunol Infect. 2020;53:368-70. https://doi.org/10.1016/j.jmii. 2020.03.005.

73. Winter PM, Dung NM, Loan HT, Kneen R, Wills B, Thu LT, et al. Proinflammatory cytokines and chemokines in humans with
Japanese encephalitis. J Infect Dis. 2004;190:1618-26. https:// doi.org/10.1086/423328.

74. Novi G, Mikulska M, Briano F, Toscanini F, Tazza F, Uccelli A, et al. COVID-19 in a MS patient treated with ocrelizumab: does immunosuppression have a protective role? Mult Scler Relat Disord. 2020;42:102120. https://doi.org/10.1016/j.msard.2020. 102120.

75. Klein RS, Garber C, Funk KE, Salimi H, Soung A, Kanmogne M, et al. Neuroinflammation during RNA viral infections. Annu Rev Immunol. 2019;37:73-95. https://doi.org/10.1146/annurevimmunol-042718-041417.

76. Tjalkens RB, Popichak KA, Kirkley KA. Inflammatory activation of microglia and astrocytes in manganese neurotoxicity. Adv Neurobiol. 2017;18:159-81. https://doi.org/10.1007/978-3-31960189-2 8 .

77. Mariani MM, Kielian T. Microglia in infectious diseases of the central nervous system. J Neuroimmune Pharmacol. 2009;4:448 61. https://doi.org/10.1007/s11481-009-9170-6.

78. Mahmoud S, Gharagozloo M, Simard C, Gris D. Astrocytes maintain glutamate homeostasis in the CNS by controlling the balance between glutamate uptake and release. Cells. 2019;8. https://doi. org/10.3390/cells8020184.

79. Cui C, Xu P, Li G, Qiao Y, Han W, Geng C, et al. Vitamin D receptor activation regulates microglia polarization and oxidative stress in spontaneously hypertensive rats and angiotensin IIexposed microglial cells: role of renin-angiotensin system. Redox Biol. 2019;26:101295. https://doi.org/10.1016/j.redox. 2019.101295.

80. Jackson L, Eldahshan W, Fagan SC, Ergul A. Within the brain: the renin angiotensin system. Int J Mol Sci. 2018;19. https://doi.org/ 10.3390/ijms 19030876.

81. Li Y, Fu L, Gonzales DM, Lavi E. Coronavirus neurovirulence correlates with the ability of the virus to induce proinflammatory cytokine signals from astrocytes and microglia. J Virol. 2004;78: 3398-406. https://doi.org/10.1128/jvi.78.7.3398-3406.2004.

82. Yang M, Li CK, Li K, Hon KLE, Ng MHL, Chan PKS, et al. Hematological findings in SARS patients and possible mechanisms (review). Int J Mol Med. 2004;14:311-5 https:// www.ncbi.nlm.nih.gov/pubmed/15254784.

83. Desforges M, Miletti TC, Gagnon M, Talbot PJ. Activation of human monocytes after infection by human coronavirus 229E. Virus Res. 2007;130:228-40. https://doi.org/10.1016/j.virusres. 2007.06.016.

84. $\mathrm{Fu} \mathrm{Y}$, Cheng $\mathrm{Y}, \mathrm{Wu} \mathrm{Y}$. Understanding SARS-CoV-2-Mediated inflammatory responses: from mechanisms to potential therapeutic tools. Virol Sin. 2020;35:266-71. https://doi.org/10.1007/ s12250-020-00207-4.

85. Mehta P, McAuley DF, Brown M, Sanchez E, Tattersall RS, Manson JJ. COVID-19: consider cytokine storm syndromes and immunosuppression. Lancet. 2020;395:1033-4 https:// linkinghub.elsevier.com/retrieve/pii/S0140673620306280.

86. Xia H, Lazartigues E. Angiotensin-converting enzyme 2: central regulator for cardiovascular function. Curr Hypertens Rep. 2010;12:170-5. https://doi.org/10.1007/s11906-010-0105-7.

87. Alenina N, Bader M. ACE2 in brain physiology and pathophysiology: evidence from transgenic animal models. Neurochem Res. 2019;44:1323-9. https://doi.org/10.1007/s11064-018-2679-4.

88. Cardin JA. Inhibitory interneurons regulate temporal precision and correlations in cortical circuits. Trends Neurosci. 2018;41:689700. https://doi.org/10.1016/j.tins.2018.07.015.

89. Zubair AS, McAlpine LS, Gardin T, Farhadian S, Kuruvilla DE, Spudich S. Neuropathogenesis and neurologic manifestations of the coronaviruses in the age of coronavirus disease 2019: a review. JAMA Neurol. 2020. https://doi.org/10.1001/jamaneurol.2020.2065.

90. Gowrisankar YV, Clark MA. Angiotensin II regulation of angiotensin-converting enzymes in spontaneously hypertensive 
rat primary astrocyte cultures. J Neurochem. 2016;138:74-85. https://doi.org/10.1111/jnc.13641.

91. Bostanciklığlu M. SARS-CoV2 entry and spread in the lymphatic drainage system of the brain. Brain Behav Immun. 2020;87: 122-3. https://doi.org/10.1016/j.bbi.2020.04.080.

92. Paniz-Mondolfi A, Bryce C, Grimes Z, Gordon RE, Reidy J, Lednicky J, et al. Central nervous system involvement by severe acute respiratory syndrome coronavirus-2 (SARS-CoV-2). J Med Virol. 2020;92:699-702. https://doi.org/10.1002/jmv.25915.

93. Baig AM, Khaleeq A, Ali U, Syeda H. Evidence of the COVID-19 virus targeting the CNS: tissue distribution, host-virus interaction, and proposed neurotropic mechanisms. ACS Chem Neurosci. 2020;11:995-8. https://doi.org/10.1021/acschemneuro.0c00122.

94. Esposito G, Pesce M, Seguella L, Sanseverino W, Lu J, Sarnelli G. Can the enteric nervous system be an alternative entrance door in SARS-CoV2 neuroinvasion? Brain Behav Immun. 2020;87:93-4. https://doi.org/10.1016/j.bbi.2020.04.060.

95. Lamers MM, Beumer J, van der Vaart J, Knoops K, Puschhof J, Breugem TI, et al. SARS-CoV-2 productively infects human gut enterocytes. Science. 2020;369:50-4. https://doi.org/10.1126/ science.abc1669.

96. Verdecchia P, Cavallini C, Spanevello A, Angeli F. The pivotal link between ACE2 deficiency and SARS-CoV-2 infection. Eur J Intern Med. 2020. https://doi.org/10.1016/j.ejim.2020.04.037.

97. Butowt R, Bilinska K. SARS-CoV-2: olfaction, brain infection, and the urgent need for clinical samples allowing earlier virus detection. ACS Chem Neurosci. 2020;11:1200-3. https://doi.org/ 10.1021/acschemneuro.0c00172.

98. Durrant DM, Ghosh S, Klein RS. The olfactory bulb: an immunosensory effector organ during neurotropic viral infections. ACS Chem Neurosci. 2016;7:464-9. https://doi.org/10.1021/ acschemneuro.6b00043.

99. LeMessurier KS, Tiwary M, Morin NP, Samarasinghe AE. Respiratory barrier as a safeguard and regulator of defense against influenza A virus and. Front Immunol. 2020;11:3. https://doi.org/ 10.3389/fimmu.2020.00003.

100. Durante MA, Kurtenbach S, Sargi ZB, Harbour JW, Choi R, Kurtenbach S, et al. Single-cell analysis of olfactory neurogenesis and differentiation in adult humans. Nat Neurosci. 2020;23:3236. https://doi.org/10.1038/s41593-020-0587-9.

101. Netland J, Meyerholz DK, Moore S, Cassell M, Perlman S. Severe acute respiratory syndrome coronavirus infection causes neuronal death in the absence of encephalitis in mice transgenic for human ACE2. J Virol. 2008;82:7264-75. https://doi.org/10.1128/JVI. 00737-08.

102. Ou X, Liu Y, Lei X, Li P, Mi D, Ren L, et al. Characterization of spike glycoprotein of SARS-CoV-2 on virus entry and its immune cross-reactivity with SARS-CoV. Nat Commun. 2020;11:1620. https://doi.org/10.1038/s41467-020-15562-9.

103. Ruiz García S, Deprez M, Lebrigand K, Cavard A, Paquet A, Arguel M-J, et al. Novel dynamics of human mucociliary differentiation revealed by single-cell RNA sequencing of nasal epithelial cultures. Development. 2019;146. https://doi.org/10.1242/dev. 177428.

104. Saraiva LR, Ibarra-Soria X, Khan M, Omura M, Scialdone A, Mombaerts P, et al. Hierarchical deconstruction of mouse olfactory sensory neurons: from whole mucosa to single-cell RNA-seq. Sci Rep. 2015;5:18178. https://doi.org/10.1038/srep18178.

105. Hoffmann M, Kleine-Weber H, Pöhlmann S. A multibasic cleavage site in the spike protein of SARS-CoV-2 is essential for infection of human lung cells. Mol Cell. 2020;78:779-84.e5. 10.1016/ j.molcel.2020.04.022

106. Thomas G. Furin at the cutting edge: from protein traffic to embryogenesis and disease. Nat Rev Mol Cell Biol. 2002;3:753-66. https://doi.org/10.1038/nrm934.

Publisher's Note Springer Nature remains neutral with regard to jurisdictional claims in published maps and institutional affiliations. 